\title{
Influence of alkaline compounds on the porosity of resorcinol- formaldehyde xerogels
}

\author{
E. G. Calvo, J.A. Menéndez, A. Arenillas* \\ Instituto Nacional del Carbón CSIC, Apartado 73, 33080 Oviedo (Spain)
}

\begin{abstract}
Carbon xerogels (CX) were prepared by means of the sol-gel polymerization of resorcinol with formaldehyde using the following alkaline additives: $\mathrm{NaOH}, \mathrm{Ca}(\mathrm{OH})_{2}, \mathrm{Na}_{2} \mathrm{CO}_{3}, \mathrm{NaHCO}_{3}$ and $\mathrm{Li}_{2} \mathrm{CO}_{3}$. Their porous and chemical structures were studied in depth using several characterization techniques. It was found that anion has a greater influence on the porous structure than cation since, in most of the cases studied, carbonate-based carbon xerogels have a larger pore size than their sodium and calcium hydroxide-based counterparts (i.e., a pore size of around $95 \mathrm{~nm}$ for carbon xerogels based on $\mathrm{OH}^{-}$vs. ca. $1000 \mathrm{~nm}$ in the case of carbonate-based xerogels, for a specific value of $\mathrm{pH}$, dilution and resorcinol/formaldehyde molar ratio). In addition, it was possible to remove the source of the sodium of the synthesis process, a highly corrosive element that damages the devices and equipment used in post-treatments. Both types of hydroxide lead to carbon xerogels with identical porous and chemical properties, except in their impurity content, which is smaller in the case of the sample produced from $\mathrm{Ca}(\mathrm{OH})_{2}$.
\end{abstract}

Keywords: Resorcinol-formaldehyde xerogel; Alkaline compounds; Impurities; Porosity

*Corresponding author. Tel.: +34 9851190 90; Fax: +34 985297662

E-mail address: aapuente@incar.csic.es (Ana Arenillas)

\section{Introduction}

Research papers published in recent years have underlined the versatility of resorcinolformaldehyde xerogels (RF xerogels), high value-added polymers due to their excellent properties and simple manufacture by microwave technology $[1,2]$. Characteristics such as porosity, density and structure can be easily modified depending on the operation variables [18]. For example, it is possible produce a very light RF gel with a high macropore volume, suitable properties that allow it to be applied as thermal insulating material [9-11], or likewise a RF gel with well-developed microporosity, property that makes it an excellent material for storing energy in supercapacitors [12-14].

The influence of variables such as $\mathrm{pH}, \mathrm{R} / \mathrm{F}$ molar ratio, dilution ratio (D) and, even, the presence 
of methanol in commercial formaldehyde solutions, on the porosity and structure of RF xerogels has been extensively investigated by the scientist community working in the field of these polymeric materials [1-8]. Of these variables, the $\mathrm{pH}$ of the resorcinol-formaldehyde mixture is the one that most affects the porosity of the final materials. The $\mathrm{pH}$ of the reaction medium regulates the polymerization mechanism between the monomers, a mechanism that occurs in two stages: (i) the base deprotonates the $\mathrm{OH}$ groups of resorcinol to $\mathrm{O}^{-}$, which facilitates the reaction between the aromatic rings and formaldehyde molecules to produce hydroxymethyl derivatives (addition reaction), and, (ii) these hydroxymethyl derivatives condense, causing colloidal particles to crosslink and form a 3D-network (condensation reaction) [1-6]. The rate of these two reactions is regulated by the value of the $\mathrm{pH}$. According to the polymerization mechanism, high $\mathrm{pH}$ values favor the first reaction and, therefore, highly branched and unstable aggregates are formed, leading to smaller more interconnected particles and, hence, to materials of smaller pore size.

Most of the carbon xerogels mentioned in the literature are obtained by basic catalysis, mainly from alkaline carbonates and hydroxides $\left(\mathrm{NaOH}\right.$ and $\mathrm{Na}_{2} \mathrm{CO}_{3}$, in most cases) [1-8, 15-17]. However, others agents such as $\mathrm{K}_{2} \mathrm{CO}_{3}, \mathrm{Li}_{2} \mathrm{CO}_{3}, \mathrm{Ca}(\mathrm{OH})_{2}, \mathrm{CH}_{3} \mathrm{COOH}$ or organic acids, have also been used by some authors to set the $\mathrm{pH}$ of aqueous resorcinol-formaldehyde mixtures [1822]. The $\mathrm{pH}$ value plays a crucial role in the reaction mechanism and in determining the porosity of RF xerogels. However, the type of alkaline additive used is also relevant. The nature of the base exerts a double influence, since it has an impact both on the volume and size of the porosity created and on the amount of impurities in the final material, as a consequence of the different ions present in the mixture.

The presence of impurities, such as alkali metals like potassium (K) and sodium (Na), halogens such as chlorine $(\mathrm{Cl})$ and other contaminants, has a negative effect because they cause corrosion and slagging of steel reactors operating at high temperatures [21, 22]. The economic impact caused by the corrosion of these reactors is very high, especially in processes developed on an industrial scale. Particularly, in the production of RF xerogels, steel reactors operating at high temperatures $\left(1000{ }^{\circ} \mathrm{C}\right.$, for example), are used during post-treatment and, more specifically, during activation processes to increase their microporosity.

In light of the problems mentioned above, the aim of this paper is twofold: on the one hand, to evaluate the influence of different bases on the porosity and chemistry of RF xerogels and, secondly, to identify the $\mathrm{pH}$ modifier that produces materials with the least amount of impurities. To this end, two types of bases were used, hydroxides and carbonates: $\mathrm{NaOH}$, $\mathrm{Ca}(\mathrm{OH})_{2}, \mathrm{Na}_{2} \mathrm{CO}_{3}, \mathrm{NaHCO}_{3}$ and $\mathrm{Li}_{2} \mathrm{CO}_{3}$. All of these were used in solid state, unlike other authors who used these bases in aqueous solutions, slightly altering the dilution ratio of the 
precursor mixture, variable which also influences on the porosity of the RF xerogels $[2,4,6,7$, $8,20]$. Although the main goal of this work was to avoid the presence of residual $\mathrm{Na}$ in the final carbon xerogels, three sodium bases were selected because they are the agents most commonly found in the literature (especially $\mathrm{NaOH}$ and $\mathrm{Na}_{2} \mathrm{CO}_{3}$ ). In addition, since they are all formed by the same cation, it will be possible to see whether the use of different anions results in materials with different properties.

\section{Materials and Methods}

\subsection{Synthesis of RF xerogels}

In order to analyze the influence of the alkaline additives on the porous and chemical properties of the RF xerogels, three different synthesis conditions (combinations of $\mathrm{pH}$, dilution, i.e. the total solvent/reactant molar ratio, and $\mathrm{R} / \mathrm{F}$ molar ratio) and five alkaline agents $(\mathrm{NaOH}$, $\mathrm{Ca}(\mathrm{OH})_{2}, \mathrm{Na}_{2} \mathrm{CO}_{3}, \mathrm{NaHCO}_{3}, \mathrm{Li}_{2} \mathrm{CO}_{3}$ ) were selected, yielding 15 carbon xerogels (see Table 1). These values of $\mathrm{pH}, \mathrm{D}$ and $\mathrm{R} / \mathrm{F}$ were selected on the basis of the results of previous studies carried out by our research group with the aim of obtaining a series of carbon xerogels with very different pore volumes and sizes. Thus, whereas some samples were composed of narrow mesopores, others exhibited a high volume of large-size macropores. Although four variables $(\mathrm{pH}$, dilution, $\mathrm{R} / \mathrm{F}$ molar ratio and $\mathrm{pH}$ modifier) were modified, each of the series 1, 2 and 3 (see Table 1) has identical operation conditions, except the nature of the $\mathrm{pH}$ modifier used, so it is possible investigate the influence of this variable independently in three different types of carbon xerogel structures (i.e. with narrow mesopores, wide mesopores and macropores).

The organic xerogels were synthesized by the polymerization of resorcinol (Indspec, $99.6 \mathrm{wt}$. $\%$ ) and formaldehyde (Química SAU, aqueous solution with $37 \mathrm{wt}$ \% formaldehyde and $0.6 \mathrm{wt}$. $\%$ of methanol), using deionized water as solvent and different alkaline salts to modify the $\mathrm{pH}$. It is important to mention that the alkaline bases were applied in solid state, so as not to modify the dilution ratio (D). The procedure consists in the addition of small amounts of alkaline agent and subsequent measurement of the solution $\mathrm{pH}$. This operation was repeated until the $\mathrm{pH}$ value desired was achieved. The amount of base added depended on the final $\mathrm{pH}$ desired as on its strength. Briefly, the microwave-assisted process involved the following stages: (i) heating at 85 ${ }^{\circ} \mathrm{C}$ for ca. 3 hours to perform the gelation and ageing stages and, (ii) heating to a temperature above $100^{\circ} \mathrm{C}$ to evaporate the water used as solvent. This stage ends when a mass loss of $50 \mathrm{wt}$. $\%$ is reached.

Once the fabrication of the organic xerogels was completed, they were thermally stabilized by a pyrolysis in a tubular horizontal furnace (Carbolite MTF 12/38/400) under a nitrogen 
atmosphere $\left(150 \mathrm{~mL} \min ^{-1}\right)$, up to $700{ }^{\circ} \mathrm{C}\left(50^{\circ} \mathrm{C} \mathrm{min}^{-1}\right)$ with a soaking time of 2 hours. The final carbon xerogels are designated in this paper as $\mathrm{X}-\mathrm{y}$, where $X$ is $\mathrm{Na}, \mathrm{Ca}, \mathrm{Na} 2, \mathrm{NaH}$ or $\mathrm{Li}_{2}$, depending on the base used, and $y$ corresponds to a numerical value, between 1 and 3 , depending on the experimental conditions used for their synthesis.

Table 1. Summary of the synthesis conditions of the RF xerogels studied in this work.

\begin{tabular}{|c|c|c|c|c|}
\hline Base & pH & D & $\mathbf{R} / \mathbf{F}$ & Nomenclature \\
\hline \multirow{3}{*}{$\mathrm{NaOH}$} & 6.5 & 5.7 & 0.5 & $\mathrm{Na}-1$ \\
\hline & 6.2 & 4.7 & 0.2 & $\mathrm{Na}-2$ \\
\hline & 5.3 & 7.7 & 0.7 & $\mathrm{Na}-3$ \\
\hline \multirow{3}{*}{$\mathrm{Ca}(\mathrm{OH})_{2}$} & 6.5 & 5.7 & 0.5 & $\mathrm{Ca}-1$ \\
\hline & 6.2 & 4.7 & 0.2 & $\mathrm{Ca}-2$ \\
\hline & 5.3 & 7.7 & 0.7 & $\mathrm{Ca}-3$ \\
\hline \multirow{3}{*}{$\mathrm{Na}_{2} \mathrm{CO}_{3}$} & 6.5 & 5.7 & 0.5 & $\mathrm{Na}_{2}-1$ \\
\hline & 6.2 & 4.7 & 0.2 & $\mathrm{Na}_{2}-2$ \\
\hline & 5.3 & 7.7 & 0.7 & $\mathrm{Na}_{2}-3$ \\
\hline \multirow{3}{*}{$\mathrm{NaHCO}_{3}$} & 6.5 & 5.7 & 0.5 & $\mathrm{NaH}-1$ \\
\hline & 6.2 & 4.7 & 0.2 & $\mathrm{NaH}-2$ \\
\hline & 5.3 & 7.7 & 0.7 & $\mathrm{NaH}-3$ \\
\hline \multirow{3}{*}{$\mathrm{Li}_{2} \mathrm{CO}_{3}$} & 6.5 & 5.7 & 0.5 & $\mathrm{Li}_{2}-1$ \\
\hline & 6.2 & 4.7 & 0.2 & $\mathrm{Li}_{2}-2$ \\
\hline & 5.3 & 7.7 & 0.7 & $\mathrm{Li}_{2}-3$ \\
\hline
\end{tabular}

\subsection{Physico-chemical characterization of the RF xerogels}

The porous and chemical properties of the samples were evaluated by means of four techniques: (i) $\mathrm{N}_{2}$ adsorption-desorption isotherms, (ii) mercury porosimetry; (iii) elemental analysis and (iv) inductively coupled plasma mass spectrometry (ICP-MS).

The nitrogen adsorption-desorption isotherms were performed at $-196{ }^{\circ} \mathrm{C}$ in an adsorption analyzer (Micromeritics Tristar 3020), after the samples had been degassed at $120{ }^{\circ} \mathrm{C}$ and 0.1 mbar for 8 hours using a Micromeritics VacPrep 0.61 device. With this technique, the following parameters were obtained: $\mathrm{S}_{\mathrm{BET}}$ and $\mathrm{V}_{\text {microo }}$, which were calculated by applying the BrunauerEmmett-Teller (BET) and Dubinin-Raduskevich (DR) equations, respectively; total pore volume $\left(\mathrm{V}_{\mathrm{p}}\right)$ estimated from the amount of nitrogen adsorbed at $\mathrm{p} / \mathrm{p}^{\mathrm{o}}=0.99$ and; pore size distribution (PSD), determined by applying the DFT method to the nitrogen adsorption branch.

The carbon xerogels with large mesoporosity or macroporosity were also evaluated by means of 
mercury porosimetry on an AutoPore IV 9500, Micromeritics, a device able to operate in a pressure range from atmospheric pressure to $228 \mathrm{MPa}$. The surface tension value and contact angle selected were $485 \mathrm{mN} \mathrm{m}^{-1}$ and $130^{\circ}$, respectively. Mercury porosimetry analysis based on the Washburn intrusion theory yielded the pore size distributions, bulk densities and mesopore/macropore volumes. The device is not able to detect pores smaller than $5.5 \mathrm{~nm}$, therefore the $\mathrm{V}_{\text {meso }}$ comprises pores ranging from 5.5 to $50 \mathrm{~nm}$.

The elemental analysis results were obtained using two different devices, a LECO-CHNS-932 microanalyzer, to determine the $\mathrm{C}, \mathrm{N}$ and $\mathrm{H}$ content and a LECO-TF-900 furnace coupled to an IR spectrometer, to measure directly the oxygen content.

The amount of residual elements resulting from the use of the diverse alkaline bases was measured by ICP-MS, on an Agilent 7700x device. Before this analysis, the carbon xerogels were subjected to microwave-assisted digestion using nitric, hydrochloric and hydrofluoric acids.

\section{Results and Discussion}

\subsection{Characterization of the pore structures of the $R F$ xerogels}

The specific surface area $\left(\mathrm{S}_{\mathrm{BET}}\right)$ values of all the carbon xerogels synthesized in this work are presented in Figure 1. At first glance, there is no outstanding difference between the samples: the $S_{\mathrm{BET}}$ is around $650 \mathrm{~m}^{2} \mathrm{~g}^{-1}$, except in the case of the three xerogels synthesized from $\mathrm{NaHCO}_{3}$, whose $\mathrm{S}_{\mathrm{BET}}$ values range from 500 to $600 \mathrm{~m}^{2} \mathrm{~g}^{-1}$. This behavior was to be expected since variables such as the $\mathrm{pH}$ or type of $\mathrm{pH}$ modifier mainly affect the meso-macroporosity of the xerogels. Microporosity usually remains unchanged, since this kind of porosity is developed during the carbonization processes $[1,2]$.

During the pyrolysis of organic xerogels, the removal of volatile matter takes place, causing an increase in microporosity. However, meso-macroporosity may also be affected to some extent, since there is a shrinkage of the xerogel structure, which can lead to a reduction in the pore size. For example, sample $\mathrm{Na}_{2}-1$ displays a $\mathrm{V}_{\text {meso }}$ value of $0.74 \pm 0.04 \mathrm{~cm}^{3} \mathrm{~g}^{-1}$ whereas after carbonization, this is reduced to $0.63 \pm 0.04 \mathrm{~cm}^{3} \mathrm{~g}^{-1}$, due to the compacting effect of the porous structure which causes some of the narrow mesopores to turn into micropores $(\mathrm{d}<2 \mathrm{~nm})$. When the xerogel comprises large macropores (e.g. $\mathrm{Na}_{2}-3$ xerogel) this phenomenon does not occur because, although the pore size is slightly reduced, they are still very large and belong to the macropore range. Therefore, the macropore volume remains almost invariable after the pyrolysis stage $\left(V_{\text {macro }}\right.$ of 1.73 and $1.79 \pm 0.04 \mathrm{~cm}^{3} \mathrm{~g}^{-1}$ for the organic and carbon xerogel $\mathrm{Na}_{2}-3$, respectively). 
With the exception of the $\mathrm{NaHCO}_{3}$-based xerogels, it seems that the trend in surface area values is $\mathrm{S}_{\mathrm{BET}}-\mathrm{R} 1>\mathrm{S}_{\mathrm{BET}}-\mathrm{R} 2>\mathrm{S}_{\mathrm{BET}}-\mathrm{R}$ 3, and this can be attributed to their porous characteristics. The samples synthesized from experimental conditions R1 have a porosity that is composed of small-to-medium size mesopores, with the five RF xerogels displaying a mesopore diameter of between 8-13 nm (see Figure 2). Conversely, recipes 2 and 3 yield meso and macroporous samples, respectively. It is well known that the BET surface area is also influenced by narrow mesoporosity and accordingly in this case, samples with narrower mesopores (xerogels R1) are those with the highest values of $S_{\mathrm{BET}}$. This phenomenon also serves to explain the lower $\mathrm{S}_{\mathrm{BET}}$ values of samples NaH-1 and NaH-2 (523 and $552 \pm 5 \mathrm{~m}^{2} \mathrm{~g}^{-1}$, respectively), since these two xerogels have a lower narrow mesopore content. The samples obtained from $\mathrm{NaOH}$ and $\mathrm{Ca}(\mathrm{OH})_{2}$ also cater to this argument. The differences between $\mathrm{S}_{\mathrm{BET}}$ values for recipes 2 and 3 are almost negligible, while the carbonates-based additives produce materials with more marked differences in their surface area. Carbonates yield carbon xerogels with larger pore size (see Figure 3 and 4), pores that not contribute to increase its specific surface area.

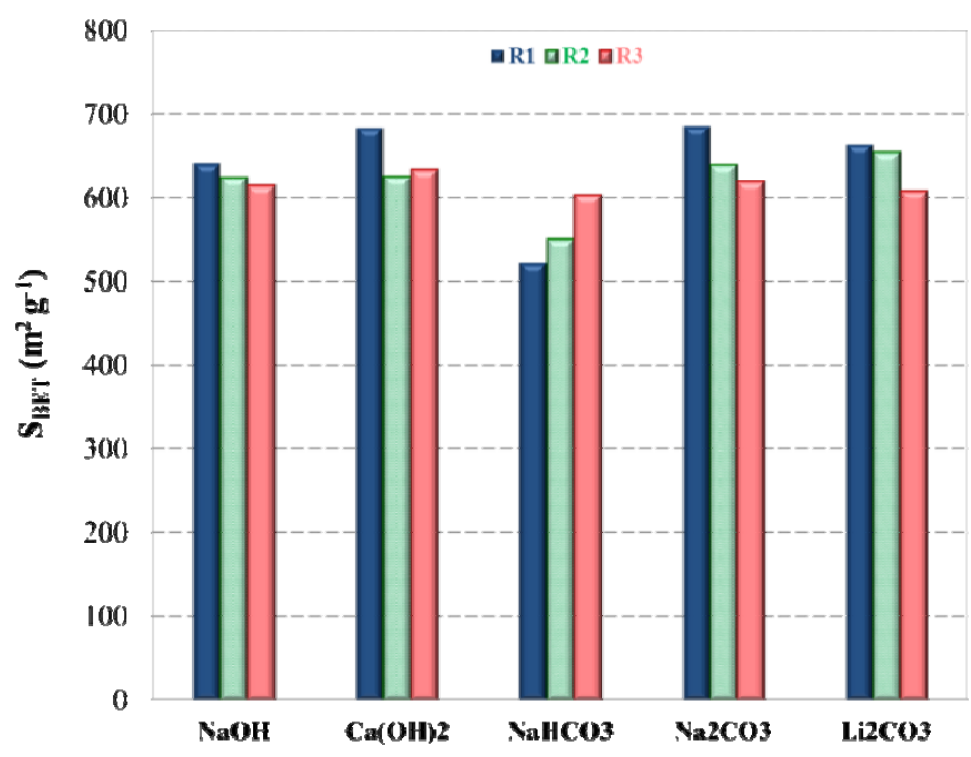

Figure 1. $S_{B E T}$ values for the carbonized RF xerogels.

Since the variables $\mathrm{pH}$, dilution and $\mathrm{R} / \mathrm{F}$ molar ratio have already been exhaustively explored by our research group $[2,3,5]$, and because the main purpose of this study is to elucidate the effect of alkaline additives on the final properties of RF xerogels, the remaining results are grouped according to the recipe used.

The RF xerogels obtained from recipe 1 (6.5-5.7-0.5) are micro-mesoporous materials composed of small-size mesopores, in agreement with the results reported by other publications on RF xerogels synthesized under identical operation conditions [2, 5]. The characteristics of their mesoporosity, with regard to volume and average mesopore diameter, are summarized in 
Figure 2. General speaking, there are no major differences in mesoporosity depending on the type of the $\mathrm{pH}$ modifier. Leaving aside sample $\mathrm{NaH}-1$, the other four xerogels have mesopore volumes between $0.4-0.6 \mathrm{~cm}^{3} \mathrm{~g}^{-1}$ with pore sizes ranging from 10 to13 $\mathrm{nm}$. Under these operation conditions, it is not easy to see any clear difference between the use of hydroxides and carbonates, and this may be due to the rapid kinetics of the polymerization reactions. Under the three experimental conditions selected, R1 results in shorter gelation times (about 10 minutes with microwave heating), and therefore, the possible effect of the catalytic species on the porous texture could be partially mitigated in this case.

If Figure 2 is examined closely, it can be seen that the base that leads to the sample with the greatest mesopore volume is sodium carbonate (i.e. $V_{\text {meso }}$ of $0.63 \pm 0.04 \mathrm{~cm}^{3} \mathrm{~g}^{-1}$ with a mean pore size of ca. $13.6 \pm 1 \mathrm{~nm}$ ). This result deserves a more detailed explanation since the same trend is repeated under the other two experimental conditions studied.

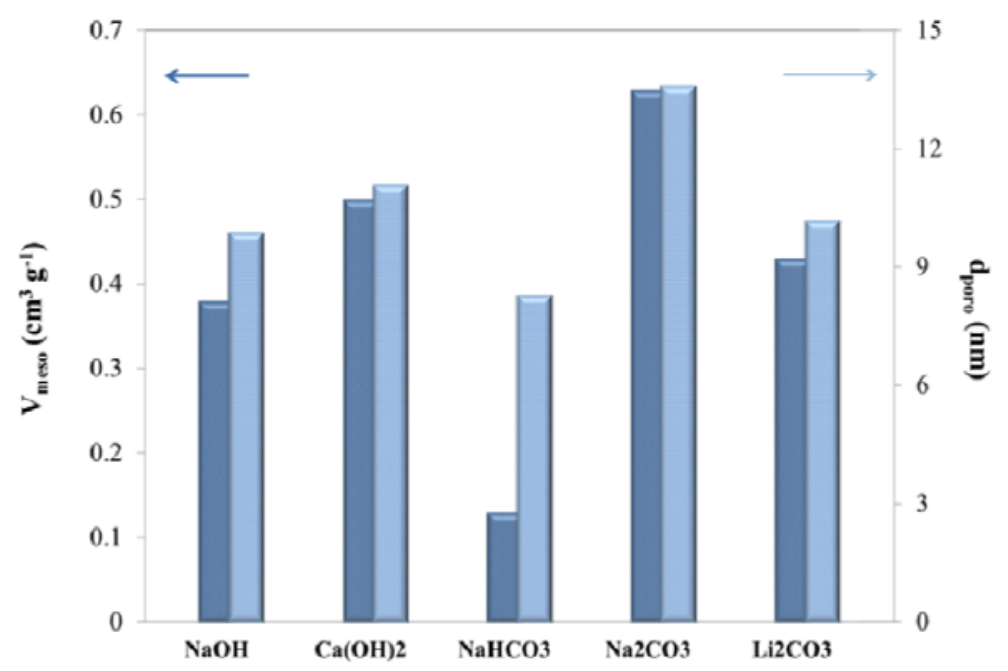

Figure 2. Mesoporosity characteristics ( $V_{\text {pore }}$ and $\left.d_{\text {pore }}\right)$ for the carbon xerogels obtained from experimental conditions R1.

Carbon xerogels obtained from the experimental conditions assigned as R2 contain a micromesoporous structure. The pore size distributions (PSD) of the five samples synthesized are shown in Figure 3: (a) PSD obtained from mercury porosimetry measurements and, (b) PSD of samples prepared using the alkaline hydroxides, obtained from $\mathrm{N}_{2}$ isotherms, since in the case of micro-mesoporous samples based on narrow mesopores, the similarities/differences are more easily identified by the $\mathrm{N}_{2}$ adsorption technique.

As can be seen, porosity differs heavily depending on whether hydroxides or carbonates were used to accelerate the polymerization process. The samples prepared from alkaline carbonates 
show a more abundant and wider mesoporosity. In addition to the differences in pore size, the larger mesopore volume is worth noting since the carbon xerogels obtained from the carbonates display mesopore volumes that are around three times greater than those fabricated from $\mathrm{NaOH}$ and $\mathrm{Ca}(\mathrm{OH})_{2}: \mathrm{V}_{\text {meso }}$ of $0.37,0.29,1.28,0.92$ and $0.99 \pm 0.04 \mathrm{~cm}^{3} \mathrm{~g}^{-1}$ for carbon xerogels Na-2, $\mathrm{Ca}-2, \mathrm{Na}_{2}-2, \mathrm{NaH}-2$ and $\mathrm{Li}_{2}-2$, respectively. One possible hypothesis for the wider porosity yielded by the carbonate compounds might be related to the different size of the $\mathrm{OH}^{-}$and $\mathrm{CO}_{3}{ }^{2-}$ anions. Carbonate ions are larger and have a trigonal planar molecular geometry that may cause some steric hindrance and, as a result, the condensation of the intermediates derivatives will generate larger pores. As occurs with carbon xerogels- $\mathrm{R} 1$, in this case, also $\mathrm{Na}_{2} \mathrm{CO}_{3}$ yields a final material with higher volume and larger pores.
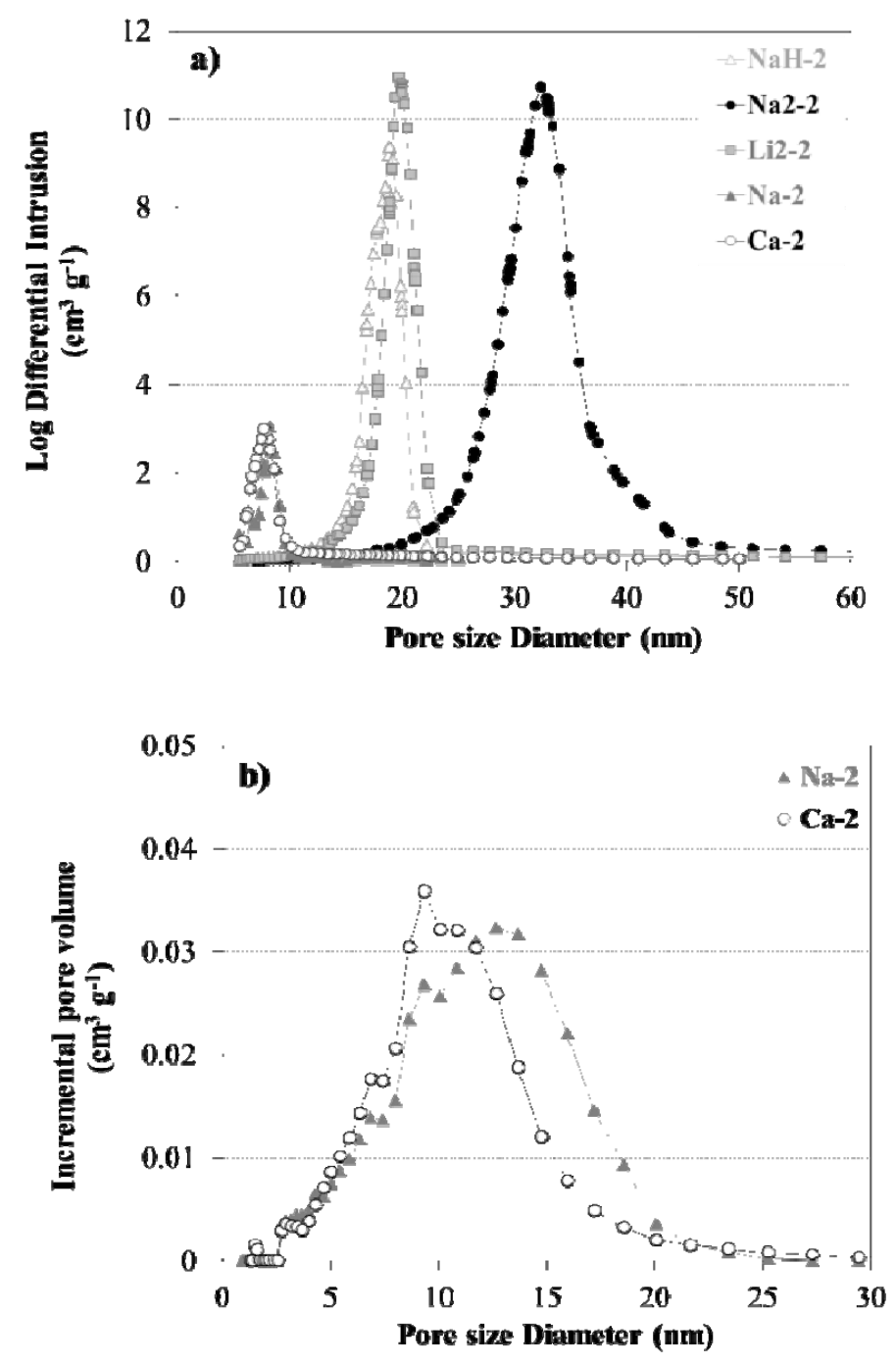

Figure 3. Pore size distributions obtained from $\mathrm{Hg}$ porosimetry (a) and $\mathrm{N}_{2}$ isotherms (b) for samples derived from $R 2$.

Figure 3 highlights the possibility of replacing sodium by calcium, without its having a serious impact on the porosity of the resulting material. Furthermore, according to the ICP-MS analysis, 
the residual $\mathrm{Na}$ content is reduced ( $\sim 800$ vs. $180 \mathrm{ppm}$ for $\mathrm{Na}-2$ and $\mathrm{Ca}-2$ xerogels, respectively). This proves that, when the $\mathrm{OH}^{-}$anion is maintained, it is possible to replace the sodium cation by calcium cation in order to obtain a carbon xerogel without sodium and with similar porosity.

The results reported so far suggest that anions make a greater contribution to porosity than cations. Several studies in the literature focus on the effect of $\mathrm{pH}$ modifier (basic or acidic) on the porosity of resorcinol-formaldehyde gels. However, they are not easy to compare because specific operating conditions were employed in each study, and even further, if one considers that the carbon xerogels of this study were synthesized with microwave radiation. Despite the different experimental conditions used, some similarities can be found with the findings proposed by other authors. For example, T. Horikawa et al. [23] prepared RF aerogels using four different compounds: $\mathrm{Na}_{2} \mathrm{CO}_{3}, \mathrm{~K}_{2} \mathrm{CO}_{3}, \mathrm{NaHCO}_{3}$ and $\mathrm{KHCO}_{3}$ and claimed that porous characteristics vary depending on the type of additive. The greatest discrepancies between the samples were in relation to mesopore volume and size and they are attributed to the gelation process varying depending on the base used. With none of the alkaline carbonates, did the fact of replacing sodium by potassium modify the porosity of the carbon aerogel, as in the case of the present study when $\mathrm{NaOH} / \mathrm{Ca}(\mathrm{OH})_{2}$ and $\mathrm{NaHCO}_{3} / \mathrm{Li}_{2} \mathrm{CO}_{3}$ were used. However, contrary to the present findings, the use of sodium carbonate instead of bicarbonate caused a decrease in both the size and pore volume $\left(\mathrm{V}_{\text {meso }}\right.$ of 0.53 and $0.79 \mathrm{~cm}^{3} \mathrm{~g}^{-1}$ for $\mathrm{Na}_{2} \mathrm{CO}_{3}$ and $\mathrm{NaHCO}_{3}$ with pore radius peaks located at 2.2 and $2.8 \mathrm{~nm}$, respectively). D. Fairén-Jimenez and co-workers [18] also used two types of carbonates $\left(\mathrm{Na}_{2} \mathrm{CO}_{3}\right.$ and $\left.\mathrm{K}_{2} \mathrm{CO}_{3}\right)$ for the manufacture of carbon aerogels. For a given set of synthesis conditions $(\mathrm{R} / \mathrm{F}=0.5, \mathrm{R} / \mathrm{W}=0.08$ and $\mathrm{pH}=6.4)$, a large variation was observed when $\mathrm{Na}_{2} \mathrm{CO}_{3}$ was replaced by $\mathrm{K}_{2} \mathrm{CO}_{3}$ since, a micro-mesoporous material was obtained with a sodium bases, whereas the use of potassium carbonate led to a micro-macroporous aerogel with a PSD centered at $660 \mathrm{~nm}$. These two examples reveal the complexity of this type of materials since different combinations of $\mathrm{pH}$, dilution and $\mathrm{R} / \mathrm{F}$ molar ratio, result in completely opposite trends. In another paper [20], alkali metal hydroxides ( $\mathrm{LiOH}$, $\mathrm{NaOH}$ and $\mathrm{KOH})$ and alkaline earth metal hydroxides $\left(\mathrm{Ca}(\mathrm{OH})_{2}, \mathrm{Ba}(\mathrm{OH})_{2}\right.$ and $\left.\mathrm{Sr}(\mathrm{OH})_{2}\right)$ were used to catalyze the sol-gel reaction of resorcinol and formaldehyde monomers. The results indicated that carbon xerogels obtained from $\mathrm{M}^{2+}$ cations display a more developed porosity (a higher volume of larger pores) than those prepared by using $\mathrm{M}(\mathrm{OH})$. The explanation for this is still unclear, although at the time it was suggested that the different charge and concentration of cations may have been responsible for the changes in the porous structure. These three examples, together with the results reported in the present paper, have brought to light the discrepancies between the different works because, whereas some authors state that the ion that plays the major role is the anion, in agreement with this study, others hold the opposite view, i.e., it is the cation that mainly defines the porosity of the final material. 
In order to complete the presentation of the porous properties of the carbon xerogels, Figure 4 illustrates the PSD, obtained by means of mercury porosimetry, of the carbon xerogels synthesized from the experimental conditions denoted as number 3. The five samples synthesized with the combination 5.3-7.7-0.7 have a micro-macroporous structure, as might be expected from their $\mathrm{pH}$ value, high dilution and $\mathrm{R} / \mathrm{F}$ molar ratio greater than the stoichiometric value. From previous studies [2,5], it is known that a high volume of macropores is obtained with a $\mathrm{pH} \leq 5$ and $\mathrm{D}>7$. As the $\mathrm{pH}$ decreases, the addition reaction is slower and hence, a smaller number of resorcinol anions are formed. The polymeric particles have enough time to grow and produce large but weakly clusters. The consequent condensation of these lightly branched groups leads to a structure composed of large-size pores. In turn, as the dilution ratio increases, the number of resorcinol and formaldehyde monomers in the mixture decreases. Therefore, in this case also, sparsely cross-linked particles are formed.

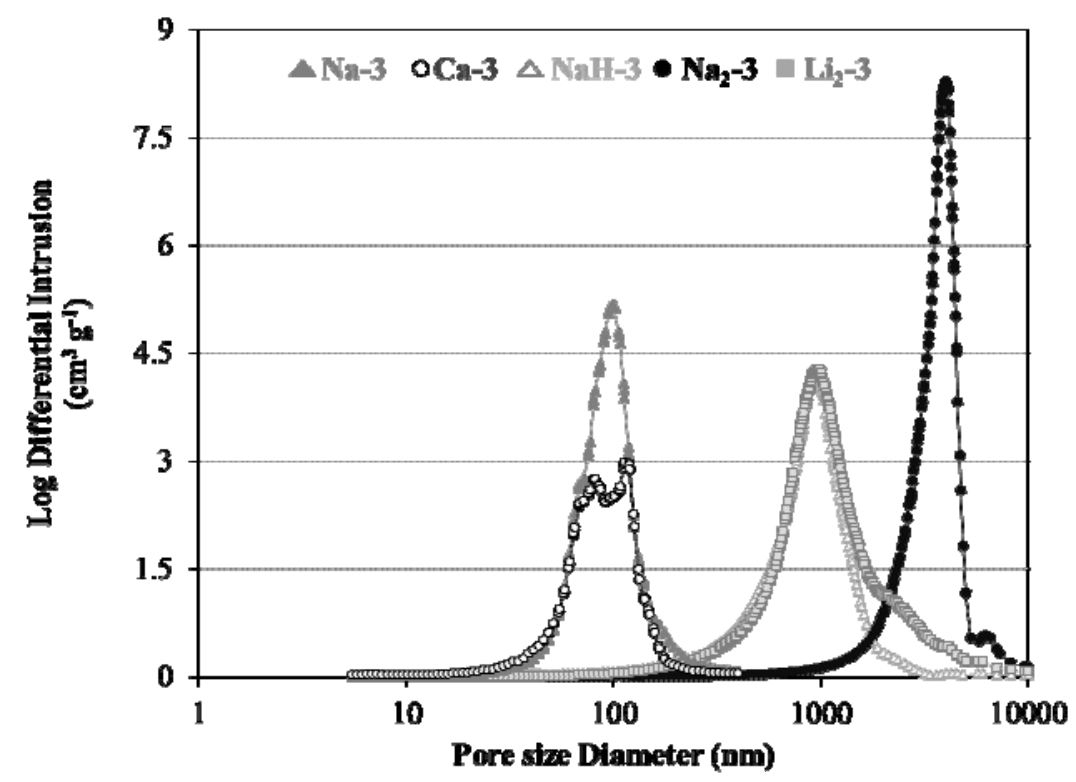

Figure 4. PSD derived from porosimetry measurements for CX obtained using 5 alkaline additives and recipe number 3.

According to the PSD, the same trend as in the CX-R2 samples is observed. Hydroxide-based compounds produce carbon xerogels with an analogous porosity and, this porosity is also narrower than that derived from alkaline carbonates (pore size around $95 \mathrm{~nm}$ for CX-hydroxides as opposed to $\sim 1000 \mathrm{~nm}$ for the samples prepared with $\mathrm{NaHCO}_{3}$ and $\mathrm{Li}_{2} \mathrm{CO}_{3}$, all of which with a macropore volume greater than $1 \mathrm{~cm}^{3} \mathrm{~g}^{-1}$ ). As in the case above, for this combination of pH-D-r, sodium carbonate is also the agent that produces the material with the largest pores. The explanation for this phenomenon is not yet fully clear but it is undeniable that it is not by 
chance, since under the three operating conditions studied, $\mathrm{Na}_{2} \mathrm{CO}_{3}$ produces RF xerogels with the greatest porous structure.

\subsection{Chemistry characteristics of the RF xerogels}

The results of the elemental analysis are presented in Table 2. The three recipes studied give rise to analogous results. Therefore, in order to avoid a too extensive table, only the data corresponding to the carbon xerogels obtained from experimental conditions R2 (6.2-4.7-0.2) have been included. As can be seen, the carbon xerogels are predominantly composed of $\mathrm{C}(\geq$ 95 wt. \%) although there is also a slight oxygen content. If the data are analyzed in detail, it becomes clear that the samples fabricated from the bases $\mathrm{Na}_{2} \mathrm{CO}_{3}, \mathrm{NaHCO}_{3}$ and $\mathrm{Li}_{2} \mathrm{CO}_{3}$ contain a higher percentage of oxygen ( $>3$ wt. $\%$ in all the cases), probably due to the presence of three oxygen atoms in each molecule, instead of 1 and 2 in the case of the $\mathrm{NaOH}$ and $\mathrm{Ca}(\mathrm{OH})_{2}$ molecules, respectively. The ash content has also been included in Table 2, and although the five samples have low ash content, $\mathrm{Ca}(\mathrm{OH})_{2}$ is the one that results in a carbon material of greatest purity.

The ICP-MS results for the R2-carbon xerogels reveal that residual $\mathrm{Na}$ was dramatically reduced when free-sodium additives were used, with a reduction in the sodium content of one order of magnitude (i.e. from $800-1400 \mathrm{ppm}$ in the case of sodium bases to ca. $200 \mathrm{ppm}$ for $\mathrm{Ca}(\mathrm{OH})_{2}$ base). It may seem surprising that, even in the case of free-sodium bases, a small amount of sodium can be detected. However, these are almost negligible quantities and they might have resulted from the manipulation of samples during the synthesis or/and characterization of the RF xerogels.

Table 2. Elemental analysis of carbon xerogels synthesized from $R 2$ conditions ( $p H: 6.2 ; D: 4.7$ and R/F: 0.2). Values related to dry samples.

\begin{tabular}{llllll}
\hline Sample & $\mathrm{Na}-2$ & $\mathrm{Ca}-2$ & $\mathrm{Na}_{2}-2$ & $\mathrm{NaH}-2$ & $\mathrm{Li}_{2}-2$ \\
\hline
\end{tabular}




\begin{tabular}{lccccc} 
C (wt. \%) \pm 0.5 & 96.3 & 96.7 & 94.9 & 95.7 & 95.1 \\
$\mathrm{H}($ wt. \%) \pm 0.5 & 1.4 & 1.5 & 1.3 & 0.8 & 1.3 \\
$\mathrm{O}($ wt. \%) \pm 0.5 & 2.1 & 1.7 & 3.6 & 3.3 & 3.3 \\
\hline Ash (wt. \%) \pm 0.2 & 0.20 & 0.14 & 0.24 & 0.20 & 0.35 \\
\hline
\end{tabular}

\section{Conclusions}

Five different alkaline species $\left(\mathrm{NaOH}, \mathrm{Ca}(\mathrm{OH})_{2}, \mathrm{Na}_{2} \mathrm{CO}_{3}, \mathrm{NaHCO}_{3}\right.$ and $\mathrm{Li}_{2} \mathrm{CO}_{3}$ ) were employed to promote the polymerization reactions between resorcinol and formaldehyde under microwave heating. The main conclusions drawn are the following:

- The alkaline compounds usually added to RF precursor solutions to adjust the desired $\mathrm{pH}$ cannot be considered as catalysts, as commonly can be found in the literature, as they take part of the reaction and define the final properties of the final material. Therefore, for the same $\mathrm{pH}$ value, it is possible to obtain two RF xerogels with different porosity by using two different compounds

- The three experimental conditions tested reveal that the additives based on hydroxides $\left(\mathrm{NaOH}\right.$ and $\left.\mathrm{Ca}(\mathrm{OH})_{2}\right)$ generate materials with a similar porosity and, in turn, this is narrower than the porosity created in carbon xerogels made by using the bases $\mathrm{Na}_{2} \mathrm{CO}_{3}$, $\mathrm{NaHCO}_{3}$ and $\mathrm{Li}_{2} \mathrm{CO}_{3}$. In other words, it seems clear that the ion that plays the most important role in determining the final porous structure of RF xerogels is the anion.

- It is possible to reduce the sodium content of carbon xerogels and so avoid corrosion of the reactors by replacing $\mathrm{NaOH}$ by some other bases. However, the type of catalytic species used must be taken into account because the porous structure may be modified. If sodium is replaced by calcium hydroxide, the resultant synthesized materials show virtually identical porous and chemical properties, in addition to a reduction in sodium content. It is for that reason that this compound is highly appropriate for attaining the main objective pursued in this work.

\section{Acknowledgements}


The authors gratefully acknowledge the financial support of Ministerio de Economía y Competitividad of Spain, MINECO (projects CTQ2013-49433-EXP and CTQ2014-54772-P).

\section{References}

[1] E.G. Calvo, J.A. Menéndez, A. Arenillas, Designing Nanostructured Carbon Xerogels, in: M.M. Rahman (Ed), Nanomaterials, 2011, pp. 187-234.

[2] N. Rey-Raap, J.A. Menéndez, A. Arenillas, RF xerogels with tailored porosity over the entire nanoscale, Micro. Meso. Mater. 195 (2014) 266-275.

[3] I.D. Alonso-Buenaposada, N. Rey-Raap, E.G. Calvo, J.A. Menéndez, A. Arenillas, Effect of metanol content in commercial formaldehyde solutions on the porosity of RF carbon xerogels, J. Non-Cryst. Solids 426 (2015) 13-18.

[4] M.L. Rojas-Cervantes, Some strategies to lower the production cost of carbon gels, J. Mater. Sci. 50 (2014) 1017-1040.

[5] N. Rey-Raap, J.A. Menéndez, A. Arenillas, Simultaneous adjustment of the main chemical variables to fine-tune the porosity of carbon xerogels, Carbon 78 (2014) 490-499.

[6] N. Job, R. Pirard, J. Marien, J.-P. Pirard, Porous carbon xerogels with texture tailored by $\mathrm{pH}$ control during sol-gel process, Carbon 42 (2004) 619-628.

[7] P. Veselá, V. Slovák, N-doped carbon xerogels prepared by ammonia assisted-pyrolysis: Surface characterization, thermal properties and adsorption ability for heavy metal ions, J. Anal. Appl. Pyrol. 109 (2014) 266-271.

[8] S.A. Al-Mutasheb, J.A. Ritter, Preparation and properties of resorcinol-formaldehyde organic and carbon gels, Adv. Mater. 15 (2003) 101-114.

[9] J. Feng, J. Feng, C. Zhang, Thermal conductivity of low density carbon aerogels, J. Porous Mater. 19 (2012) 551-556.

[10] J. Feng, J. Feng, Y. Jiang, C. Zhang, Ultralow density carbon aerogels with low thermal conductivity up to $2000^{\circ} \mathrm{C}$, Mater. Letters 65 (2011) 3454-3456.

[11] M. Wiener, G. Reichenauer, S. Braxmeier, F. Hemberger, H.-P. Ebert, Carbon AerogelBased High-Temperature Thermal Insulation, Int. J. Thermophys. 30 (2009) 1372-1385. 
[12] E. Frackowiak, Carbon materials for supercapacitor application, Phys. Chem. Chem. Phys 9 (2007) 1774-1785.

[13] E.G. Calvo, F. Lufrano, P. Staiti, A. Brigandì, A. Arenillas, J.A. Menéndez, Optimizing the electrochemical performance of aqueous symmetric supercapacitors based on an activated xerogel, J. Power Sources 241 (2013) 776-782.

[14] Y.-M. Chang, C.-Y. Wu, P.-W. Wu, Synthesis of large surface area carbon xerogels for electrochemical double layer capacitors, J. Power Sources 223 (2013) 147-154.

[15] A.M. Elkhatat, S.A. Al-Muhtaseb, Advances in tailoring resorcinol-formaldehyde organic and carbon gels, Adv. Mater. 23 (2011) 2887-2903.

[16] B.S. Girgis, I.Y. El-Sherif, A.A. Attia, N.A. Fathy, Textural and adsorption characteristics of carbon xerogels adsorbents for removal of $\mathrm{Cu}$ (II) ions from aqueous solution, J. Non-Cryst. Solids 358 (2012) 741-747.

[17] K.Z. Gaca, J. Sefcik, Mechanism and kinetics of nanostructure evolution during early stages of resorcinol-formaldehyde polymerization, J. Colloid Interf. Sci. 406 (2013) 51-59.

[18] D. Fairén Jiménez, F. Carrasco-Marín, C. Moreno-Castilla, Porosity and surface area of monolithic carbon aerogels prepared using alkaline carbonates and organic acids as polymerization catalyst, Carbon 44 (2006) 2301-2307.

[19] H.Y. Tian, C.E. Buckley, M. Paskevicius, D.A. Sheppard, Acetic acid catalysed carbon xerogels derived from resorcinol-furfural for hydrogen storage, Int. J. Hydrogen Energ. 36 (2011) 671-679.

[20] N. Job, C.J. Gommes, R. Pirard, J.-P. Pirard, Effect of the counter-ion of the basification agent on the porous texture of organic and carbon xerogels, J. Non-Cryst. Solids 354 (2008) 4698-4701.

[21] H. Liu, M. Saffaripour, P. Mellin, C.-E. Grip, W. Yang, W. Blasiak, A thermodynamic study of hot syngas impurities in steel reheating furnaces - Corrosion and interaction with oxide scales, Energy 77 (2014) 352-361.

[22] M.A. Uusitalo, P.M.J. Vuoristo, T.A. Mäntylä, High temperature corrosion of coatings and boiler steels below chlorine-containing salt deposits, Corros. Sci. 46 (2004) 1311-1331.

[23] T. Horikawa, J. Hayashi, K. Muroyama, Controllability of pore characteristics of resorcinol-formaldehyde carbon aerogel, Carbon 42 (2004) 1625-1633. 